\title{
SPECIFICITIES IN OPTICAL ABSORPTION OF ULTRATHIN MOLECULAR FILM-STRUCTURES
}

\author{
J. P. Šetrajčićl, ${ }^{1 *}$, D. Lj. Mirjanić ${ }^{2}$ \\ ${ }^{1}$ University of Novi Sad, Faculty of Sciences, Department of Physics, \\ 21000 Novi Sad, Trg Dositeja Obradovića 4, Vojvodina, Serbia \\ ${ }^{2}$ The Academy of Sciences and Arts of the Republic of Srpska, 78000 Banja Luka, \\ Trg srpskih vladara 2/2, Republic of Srpska, B\&H
}

\begin{abstract}
This paper represents a theoretical study of changes of fundamental optical properties in symmetric perturbed quasi-two-dimensional structures - nanofilm molecular crystal patterns. The energy spectrum and the state of excitons, as well as their spatial distribution along the border layer (by layers) was found on the basis of adjusted Green's functions and analytic-numerical calculations. Relative permittivity was determined and the influence of limit parameters on the occurrence of resonant absorption was studied. Dependence of the absorption index on the frequency of external electromagnetic field was found and selective absorption defined with nanofilms with symmetric border surfaces.

Keywords: Excitons, nanostructures, Green's functions, permittivity, absorption index, resonant absorption.
\end{abstract}

\section{INTRODUCTION}

Materials from the class of non-metal molecular crystals have been known for a long time by their absorption characteristics. Namely, if we set bulk structures (spatially unlimited molecular crystals in all three dimensions) within an internal electromagnetic field, we can measure the dielectric permittivity, i.e. absorption characteristics of these crystals, because the connection between the dielectric permittivity and the index of refraction has already been known for a long time. The bulk structures will absorb a certain broader range of energies of external electromagnetic radiation, depending on which atoms or molecules make the crystal and on their resonant excitation energies. Resonant response of bulk structures to the external electromagnetic field with molecular non-metal materials (dielectric, insulator) can be described by way of exciton mechanism: pairing of electrons and holes occurs in crystal, and we call this pair exciton. With metals, due to a big number (and density) of excitons, such binding of excitons with holes would simply not occur. Exciton is a quasi-particle, we can attribute to it effective mass, it is electrically neutral and cannot transport electricity, but can transport energy. Excitons are the particles that are responsible for absorption of external radiation. This paper investigates, in a theoretical manner, what would happen with absorption characteristics if we made an ultrathin film from a molecular crystal, ultrathin film being a structure the dimensions of which can be considered endless, with one dominant direction finite and equal to thickness of dozens of atomic planes.

So, in this paper we have observed the ultrathin dielectric films (the thickness of which does not exceed a dozen of atomic planes). Typical representatives of such structures are molecular crystals and in them the elementary excitations appear - i.e. excitons in the result of interaction of external electromagnetic field in electron of crystal. By way of dispersion law of excitons and their density of state, relative permittivity is defined in the theoretical terms, and through it, optical properties of the observed system.

\section{MICROSCOPIC AND OPTICAL PROPERTIES OF BULK MOLECULAR CRYSTALS}

We started our analysis with Hamiltonian, which has the following form [1,2]:

$$
\begin{aligned}
H= & \sum_{\vec{n}} \Delta_{\vec{n}} P_{\vec{n}}^{+} P_{\vec{n}}-\sum_{\vec{n} \vec{m}} X_{\vec{n} \vec{m}} P_{\vec{n}}^{+} P_{\vec{m}}- \\
& -\sum_{\vec{n} \vec{m}} Y_{\vec{n} \vec{m}} P_{\vec{n}}^{+} P_{\vec{n}} P_{\vec{m}}^{+} P_{\vec{m}},
\end{aligned}
$$


whereby $P_{\vec{n}, \vec{m}}^{+}$are creation, and $P_{\vec{n}, \vec{m}}$ annihilation Pauli-operators; $\Delta_{\vec{n}}$ exciton energy on node $\vec{n}$, a $X_{\vec{n}, \vec{m}}$ and $Y_{\vec{n}, \vec{m}}$ are matrix elements of bipolar interactions, i.e. energies of exciton transfer from node $\vec{n}$ to $\vec{m}$. In approximation of the closest neighbors and transition in Bose statistics (by replacing Pauli operators with boson [3], in the lowest approximation) we obtain a standard effective exciton Hamiltonian, which in harmony approximation $[1,2]$ has the following form:

$$
H=\sum_{\vec{n}} \Delta_{\vec{n}} B_{\vec{n}}^{+} B_{\vec{n}}+\sum_{\vec{n}, \vec{m}} X_{\vec{n} \vec{m}} B_{\vec{n}}^{+} B_{\vec{m}},
$$

whereby $B_{\vec{n}}^{+}$and $B_{\vec{n}}$ are now creation and annihilation exciton operators. It is assumed in the model that the energy of exciton on node is $\sim 10^{2}$ times bigger than the energy of its transfer $\left(\Delta /|X| \sim 10^{2}\right)$.

We will perform microtheoretical analysis by the method of two-time temperature Green's functions $[4,5]$ due to the convenience offered by this method $^{1}$. For that purpose we observe the Green's function: $G_{\vec{n} \vec{m}}(t)=\left\langle\left\langle B_{\vec{n}}(t) \mid B_{\vec{m}}^{+}(0)\right\rangle\right\rangle$, which satisfies the following movement equation:

$$
\begin{aligned}
& i \hbar \frac{d}{d t} G_{\vec{n} \vec{m}}(t)=i \hbar \delta(t) \delta_{\vec{n} \vec{m}}+ \\
& +\Delta_{\vec{n}} G_{\vec{n} \vec{m}}(t)+\sum_{\vec{l}} X_{\vec{n} \vec{l}} G_{\vec{l} \vec{m}}(t)
\end{aligned} .
$$

By way of full time and spatial Fourier transform we can obtain the form of Green's function in $\vec{k}$-space, and from its pole the requested dispersion of excitons law too:

$$
\hbar \omega_{\vec{k}}=\Delta+2\left(X_{x} \cos a_{x} k_{x}+X_{y} \cos a_{y} k_{y}+X_{z} \cos a_{z} k_{z}\right)
$$

which, in addition to $X_{x}=X_{y}=X_{z} \equiv-|X|$ : $a_{x}=a_{y}=a_{z} \equiv a$, can also be written in the following non-dimensional form:

$$
\begin{gathered}
E(\vec{k}) \equiv \frac{\hbar \omega_{\vec{k}}-\Delta}{|X|}=R_{x y}+S_{z} ; \\
R_{x y} \equiv R\left(k_{x} k_{y}\right)=2\left(\cos a k_{x}+\cos a k_{y}\right) ; \\
S_{z} \equiv S\left(k_{z}\right)=2 \cos a k_{z}
\end{gathered}
$$

If we look at the dependence of relative energy on the wave vector, but through the parameter function $R_{x y} \in[-4 ;+4]$, we can infer that all the

${ }^{1}$ Realistic parts of poles of Green's functions define the energies of elementary excitations (from which the dispersion law is derived), while the imaginary parts are proportional to reciprocal values of the time life of these excitations. allowed exciton energies are continuously distributed in the interval of change of another parameter function $S_{z} \in[-2 ;+2]$. Graphical presentation of the dispersion law in bulk has the form provided in figure 1, and shows: $E(\vec{k})=F_{S}(R)$; whereby $R \equiv R_{x y}$ and $S \equiv S_{z}$.

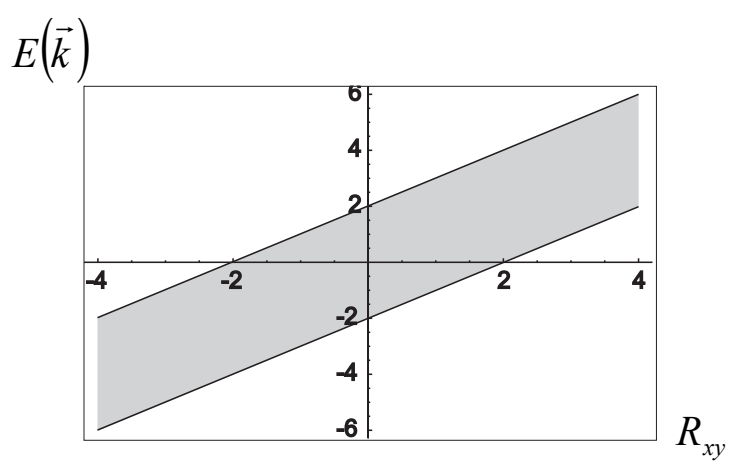

Figure 1. Law of dispersion of excitons in the bulk

We can see from the graph that the allowed energies of excitons in spatially unlimited and structurally-non-deformed molecular crystals are continuously distributed within a single area the width of which is defined by the parameter:

$$
\left.\Delta S_{z}\right|_{R_{x y}=\text { const }} \equiv\left|S_{z}^{\max }-S_{z}^{\min }\right|_{R_{x y}=0}=4 \text {, and the length }
$$

of which along the abscissa is defined by parameter: $\Delta R_{x y} \equiv\left|R_{x y}^{\max }-R_{x y}^{\min }\right|=8$.

All these energy states are equivalent and equally accessible to any exciton, no matter in where in the crystal it is found. This means that the probability for exciton in one node to have any of these energies is the same and that the spatial distribution of one (any) of these energies is equal, regardless of its position in the crystal. We can say that all the states are equally represented.

Our task is to determine optical, i.e. absorption characteristics of molecular structures. This is done via searching dielectric response of the system to variable external electromagnetic field $[6,7]$. As part of this approach, dielectric permittivity is defined by way of a general expression:

$\varepsilon^{-1}(\omega)=1-2 \pi i S[G(\omega)+G(-\omega)]$,

whereby $S$ is a parameter of internal structure. If we substitute Green's functions in this expression, we obtain an expression for dynamic permittivity of bulk:

$$
\varepsilon^{-1}=1+2 S \frac{\omega_{\vec{k}}}{\omega^{2}-\omega_{\vec{k}}^{2}} .
$$

Dependence of that permittivity is presented in Figure 2a. 
Dielectric permeability i.e. permittivity in case of existence of dispersion is a complex parameter (frequency dispersion of dielectric permeability $\varepsilon(\omega)$ implies its dependence on frequency $\omega)$, i.e. it can be expressed via realistic and imaginary part: $\varepsilon(\omega)=\varepsilon^{\prime}(\omega)+i \varepsilon^{\prime \prime}(\omega)$. By way of simple relations $\varepsilon^{\prime}$ and $\varepsilon^{\prime \prime}$ they are connected with optical characteristics of the environment: index of refraction and absorption ratio (Kramers-Kronig relations). Early enough Maxwell demonstrated that dielectric constant of a substance is equal to the index of refraction: $\varepsilon(\omega) \equiv \eta^{2}(\omega)$. If we introduce a complex index of refraction: $\eta=n+i \kappa$, we smoothly arrive at: $\varepsilon^{\prime}(\omega)=n^{2}-\kappa^{2} ; \varepsilon^{\prime \prime}(\omega)=2 n \kappa$. Based on that, we can find an expression for the absorption index in the following formula:

$\kappa(\omega)=\sqrt{\frac{\varepsilon^{\prime}(\omega)}{2}\left\{\sqrt{1+\left[\frac{\varepsilon^{\prime \prime}(\omega)}{\varepsilon^{\prime}(\omega)}\right]^{2}}-1\right\}}$.

This very important characteristic of a substance is presented in Figure $2 b$, in the function of frequency of external electromagnetic field.

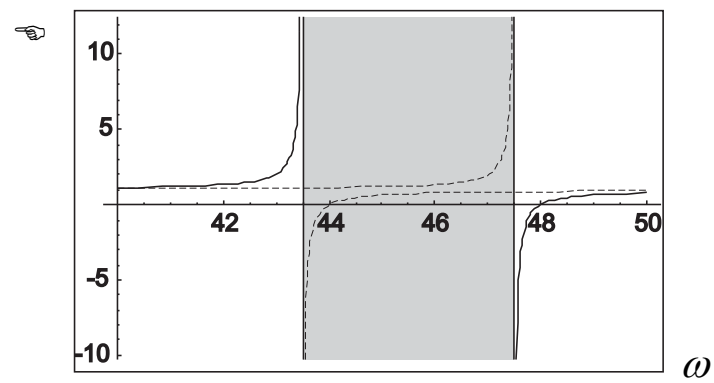

Figure 2a. Bulk permittivity

$\odot$

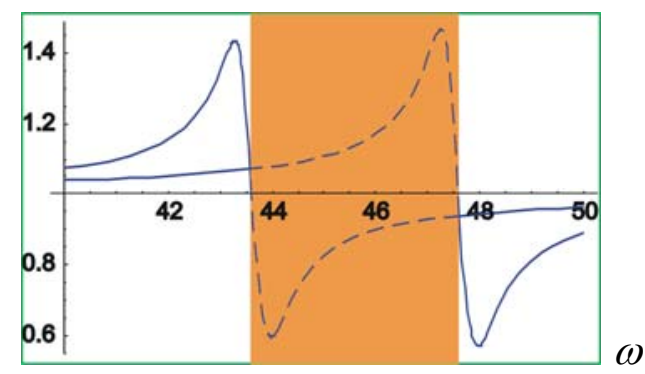

Figure 2b. Index of bulk absorption

In case of bulk, we have found that allowed energy states assume continual values, within a certain range (area) of energies, and by it, the dependence of bulk permittivity, i.e. of dielectric response creates an absorption area in which bulk will "swallow" all energies (i.e. frequencies of electromagnetic field) within a precisely defined range.

\section{LAW OF DISPERSION OF EXCITONS IN FILM}

Films are systems limited by two parallel surfaces [8-11]. Dimensions of crystal nanofilm are such that $X Y$ is unlimited, while in $z$-direction it has a finite thickness $L=N a$, i.e. $n_{z}=0,1,2, \ldots, N$, $N \propto 10, \quad n_{\alpha} \in\left[-N_{\alpha} / 2,+N_{\alpha} / 2\right], \quad N_{\alpha} \propto 10^{8}$, $\alpha=(x, y)$.

We will consider the symmetric nano-film (Figure 3) which can be made by way of controlled reaching of massive patterns $[9,10]$. Due to the existence of border surfaces, energies of excitons on nodes as well as transfers of energy between border planes $\left(n_{z}=0 ; n_{z}=N\right)$ and their adjacent planes $\left(n_{z}=1 ; n_{z}=N-1\right)$ are perturbed $[12,13]$ :

$$
\begin{aligned}
\Delta_{\vec{n}} & \equiv \Delta\left[1+d\left(\delta_{n_{z}, 0}+\delta_{n_{z}, N}\right)\right] ; \\
X_{\vec{n}, \vec{n}+\vec{\lambda}} & \equiv X\left[1+x\left(\delta_{n_{z}, 0}+\delta_{n_{z}, N-1}\right)\right] ; \\
X_{\vec{n}, \vec{n}-\vec{\lambda}} & \equiv X\left[1+x\left(\delta_{n_{z}, 1}+\delta_{n_{z}, N}\right)\right],
\end{aligned}
$$

whereby the parameter $d$ defines perturbation on the node of border surfaces, and parameter $x$ perturbation of transfer in border layers along the $z$ direction.

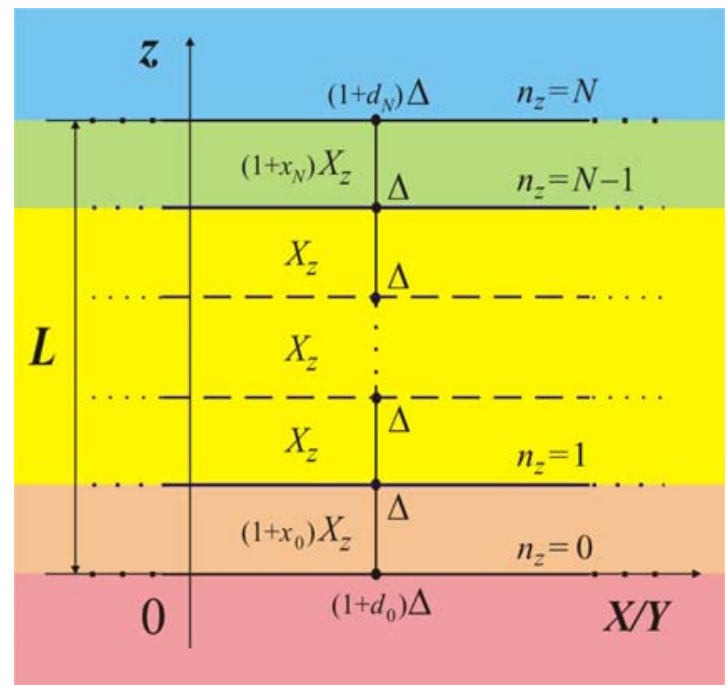

Figure 3. Model of symmetric nano-film

We will perform microtheoretical analysis of exciton sub-system in ultrathin (crystal) molecular films, by using the same method as for bulk - by the method of Green's functions. We will look at the same Green's functions and use the same procedure for their determination. Taking into account the border conditions (7) and expressions for Hamiltonian (1) as well as the equation of motion (2), we arrive at the equation for the requested Green's functions 
$[12,13]$. After full time and now only partial spatial Fourier transform of these equations, we arrive at:

$$
\begin{aligned}
& G_{n_{z}, m_{z}}\left[\rho-\frac{\Delta}{|X|} d\left(\delta_{n_{z}, 0}+\delta_{n_{z}, N}\right)\right]+ \\
& +G_{n_{z}+1, m_{z}}\left[1+x\left(\delta_{n_{z}, 0}+\delta_{n_{z}, N-1}\right)\right]+ \\
& +G_{n_{z}+1, m_{z}}\left[1+x\left(\delta_{n_{z}, 1}+\delta_{n_{z}, N}\right)\right]=\frac{i \hbar}{2 \pi|X|} \delta_{n_{z}, m_{z}},
\end{aligned}
$$

whereby: $\rho=\frac{\hbar \omega-\Delta}{|X|}+2\left(\cos a k_{x}+\cos a k_{y}\right)$. The equation (8) represents a system of $N+1$ of nonhomogenous algebraic differential equations for Green's functions. Only the poles of these functions are necessary to find the dispersion laws, therefore it is sufficient to equalize the system determinant (8) with zero:

$$
\begin{gathered}
D_{N+1}(\rho)=\left(\rho-\frac{\Delta}{|X|} d\right)^{2} C_{N_{z}-1}- \\
-2\left(\rho-\frac{\Delta}{|X|} d\right)(1+x)^{2} C_{N_{z}-2}+ \\
+(1+x)^{4} C_{N_{z}-3} \equiv 0
\end{gathered}
$$

whereby $C_{N}$ are Chebyshev polynomials of $\mathrm{N}$ order with characteristic $C_{N-1}=\rho C_{N}-C_{N+1}$. In this manner we arrive at $N+1$ solution: $\rho \equiv \rho_{v}$; $v=1,2,3, \ldots, N$.

We will also present the dispersion law of excitons of the observed film in non-dimensional form: we will have the values of reduced energies on ordinates

$$
E_{v}=\frac{\hbar \omega-\Delta}{|X|} \equiv \rho_{v}-R_{x y},
$$

depending on the function $R_{x y} \equiv 2\left(\cos a k_{x}+\right.$ $\cos a k_{y}$ ) on abscissas. In Figure 4, the dispersion laws are presented, more precisely: for non-perturbed (left), $x$-perturbed (in the middle) and for $d$ perturbed (right) symmetrical five-plane or four-layer $(N=4)$ film, respectively. Full lines represent discreet energy levels of excitons in the observed film, while the intermittent lines mark the boundaries of continual energy area of excitons in the bulk.

At first sight, we can already notice the absence of zero and discreetness of exciton energies in the film. The occurrence of non-zero energy states for $k_{z}=k_{z}^{\min }>0$ and $\left(k_{x}, k_{y}\right) \in[0, \pi / a]$ is known as a consequence of QSE and $\mathrm{ShC}^{2}[11,13-15]$ and for $k_{x}=k_{y}=0$ it is called activation energy gap [912]. The number of possible exciton states corresponds to the number of crystallographic planes of this film along the $z$-axis. The figures further show that, with an increase of parameter $d$, a non-symmetrical spreading of energy area occurs, in the way that these two energy levels are moved toward higher energies and exit outside (above) the bulk limits. The increase in $x$ parameter leads to symmetrical spreading of the spectrum and the exit of two energy levels above the bulk borders (one above and one below the borders of the bulk area). For greater values of perturbation parameter $x$ it is possible that as many as 4 energy states (of the total of 5 allowed) „leave" the bulk area (symmetrically: 2 above and 2 below). In case that parameter $d$ assumes grater values too, 4 states that were singled out will be more prominently expressed and asymmetrically distributed compared to the bulk area. These energy conditions are known as localized or Tamm states [1,2,9-12].

The occurrence of out-bulk separated or localized states has nothing to do with exclusive QSE and/or with ShC, but is an exclusive consequence of the changed border conditions existence, i.e. the influence of a different type of material of external environment of film-structure, and, hence - of changes of exciton characteristics on border surfaces and in border layers of that film [16-18].

Such (interim) results raise a number of fundamental questions. First, what the probability for exciton to assume the state with the lowest energy (equal to the size of activation energy gap) or find itself in a localized state is. Further, where the excitons with the lowest energy (i.e. in basic state) are and what the spatial distribution of localized exciton states is. Finally, the answer should also be sought as to what is the role of occurrence of exciton gap and forming localized states in changes of fundamental (macroscopic) physical properties of ultrathin filmstructures compared to bulk patterns of the same crystallographic structure (composition).

\footnotetext{
${ }^{2}$ QSE $=$ Quantum Size Effect; ShC $=$ Shape Confine-
} 

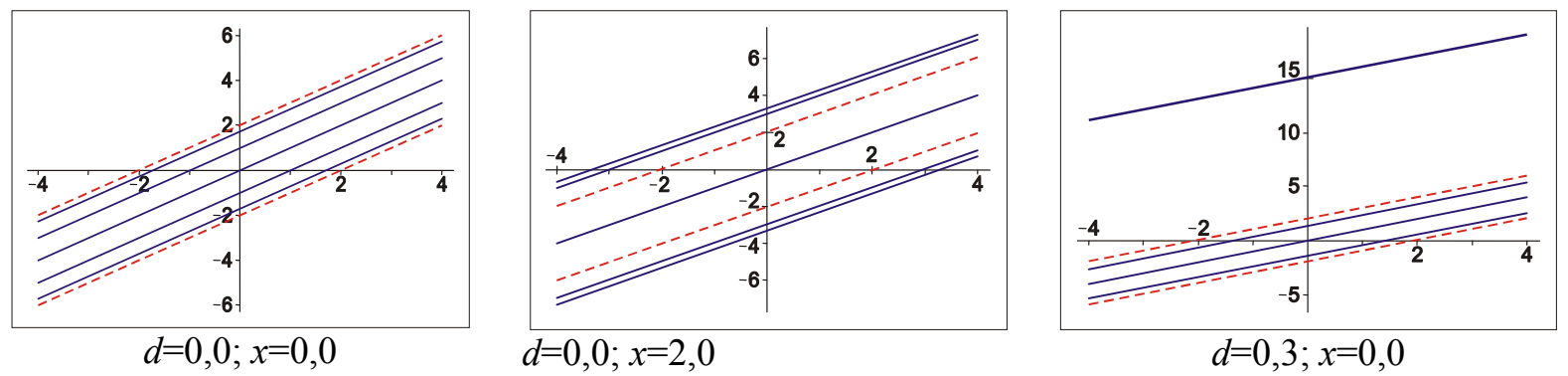

Figure 4. The dispersion law of symmetrical four-layer film

\section{PROBABILITIES OF EXCITON STATES IN FILM STRUCTURE}

Spectral weights of individual Green's functions should be calculated in order to find the probability of occurrence and spatial distribution of exciton states in a film. The starting point is the system of equations for Green's functions (8), but written in a matrix form:

$$
\hat{D}_{N+1} \widetilde{G}_{N+1}=\hat{K}_{N+1} \text {, }
$$

whereby $\hat{D}_{N+1}$ is a matrix that corresponds to the system determinant, and $\widetilde{G}_{N+1}$ and $\widetilde{K}_{N+1}$ are the vectors of Greens' functions and Kronecker deltas, respectively. If in (9) we act by invertible matrix $\hat{D}_{N+1}^{-1}$ from the left and knowing that invertible matrix can be expressed by way of adjugate matrix, the members of which $D_{i k}$ are co-factors of element
$D_{i k}$ of direct matrix, by further computation we can arrive at Green's functions, in the nominators of which directly figure spectral weights $g_{n_{z}}\left(\rho_{v}\right)$, i.e. probabilities of finding exciton states $\rho_{v}[11-13]$ :

$$
G_{n_{z}}=-\frac{i \hbar}{2 \pi|X|} \sum_{v=1}^{N+1} \frac{g_{n_{z}}\left(\rho_{v}\right)}{\rho-\rho_{v}} .
$$

The table below presents the results of calculation of spectral weights for five-layer molecular film. Probabilities are calculated by the energies that excitons may have in the film, as well as by film layers. Energies and probabilities of localized (outof-bulk) states, as well as the most probable states in the given layer are written in bold letters. The highest energy corresponds to the biggest perturbation, and all localized states are doubled (they overlap).

Table 1. Spectral weights of excitons in symmetrical four-layer film

\begin{tabular}{|r|r|r|r|r|r|}
\hline \multirow{2}{*}{ Energies } & \multicolumn{5}{|c|}{$d=0,0 ; x=0,0$} \\
\cline { 2 - 6 } & 1st plane & 2nd plane & 3rd plane & 4th plane & 5th plane \\
\hline$-1,73205$ & 0,08333 & 0,25000 & 0,33333 & 0,25000 & 0,08333 \\
\hline$-1,00000$ & 0,25000 & 0,25000 & 0,00000 & 0,25000 & 0,25000 \\
\hline 0,00000 & 0,33333 & 0,00000 & 0,33333 & 0,00000 & 0,33333 \\
\hline 1,00000 & 0,25000 & 0,25000 & 0,00000 & 0,25000 & 0,25000 \\
\hline 1,73205 & 0,08333 & 0,25000 & 0,33333 & 0,25000 & 0,08333 \\
\hline & \multicolumn{5}{|c|}{$d=0,0 ; x=2,0$} \\
\cline { 2 - 6 } Energies & 1st plane & 2nd plane & 3rd plane & 4th plane & 5th plane \\
\hline$-3,31663$ & 0,20454 & 0,25000 & 0,09090 & 0,25000 & 0,20454 \\
\hline$-3,00000$ & 0,25000 & 0,25000 & 0,00000 & 0,25000 & 0,25000 \\
\hline 0,00000 & 0,09090 & 0,00000 & 0,81818 & 0,00000 & 0,09090 \\
\hline 3,00000 & 0,25000 & 0,25000 & 0,00000 & 0,25000 & 0,25000 \\
\hline 3,31663 & 0,20454 & 0,25000 & 0,09090 & 0,25000 & 0,20454 \\
\hline & \multicolumn{5}{|c|}{$d=0,3 ; x=0,0$} \\
\cline { 2 - 7 } & 1 st plane & 2 nd plane & 3rd plane & 4 th plane & 5 th plane \\
\hline \multirow{2}{*}{ Energies } & 0,00094 & 0,25489 & 0,48833 & 0,25489 & 0,00094 \\
\hline$-1,44497$ & 0,00219 & 0,49780 & 0,00000 & 0,49780 & 0,00219 \\
\hline$-0,06635$ & 0,00130 & 0,24287 & 0,51163 & 0,24287 & 0,00130 \\
\hline 1,37794 & 0,49780 & 0,00219 & 0,00000 & 0,00219 & 0,49780 \\
\hline 15,06635 & 0,49774 & 0,00223 & 0,00003 & 0,00223 & 0,49774 \\
\hline 15,06693 & &
\end{tabular}


It is in border layers that the excitons will be localized with the highest probabilities. Therefore, the skin effect is more probable with disrupted transport factors.

\section{OPTICAL PROPERTIES OF MOLECULAR FILM}

When determining dynamic permittivity of film we shall use the general expression (5), only taking account that the Green's functions, as well as the permittivity, depend on the position of crystallographic planes of the film $n_{z}$ :

$$
\varepsilon_{n_{z}}^{-1}(\omega)=1-2 \pi i S\left[G_{n_{z}}(\omega)+G_{n_{z}}(-\omega)\right] \text {. }
$$

By incorporating the expression for Green's functions (10) we arrive at:

$\varepsilon_{n_{z}}^{-1}(\omega)=1-\frac{\hbar S}{|X|} \sum_{v=1}^{N+1} \sum_{s=+,-} \frac{g_{n_{z}}^{v}}{\rho_{s}-\rho_{v}}$,

whereby: $\quad \rho_{ \pm}=\frac{\mp \hbar \omega-\Delta}{|X|}+2\left(\cos a k_{x}+\cos a k_{y}\right)$.

With a little analytic organization and by designation $\frac{\Delta}{|X|} \equiv|p|$, the following is obtained:

$$
\varepsilon_{n_{z}}(\omega)=\left\{1-\frac{2 \hbar S}{|X|} \sum_{v=1}^{N+1} g_{n_{z}}^{v} \frac{\rho_{\nu}-|p|-2\left(\cos a k_{x}+\cos a k_{y}\right)}{\left(\frac{\hbar \omega}{|X|}\right)^{2}-\left[\rho_{\nu}-|p|-2\left(\cos a k_{x}+\cos a k_{y}\right)\right]^{2}}\right\}^{-1}
$$

This expression represents dependence of relative dynamic permittivity on relative frequency of initial external electromagnetic excitation, with a graphical presentation of this dependence shown in Figure 5 for symmetrical four-layer film.

This expression represents dielectric response of the observed molecular film to the external electromagnetic excitation. As with the bulk, we will introduce here a complex permittivity too: $\varepsilon_{n_{z}}(\omega)=$ $=\varepsilon_{n_{z}}^{\prime}(\omega)+i \varepsilon_{n_{z}}^{\prime \prime}(\omega)$, so that we can express the film absorption index:

$$
\kappa_{n_{z}}(\omega)=\sqrt{\frac{\varepsilon_{n_{z}}^{\prime}(\omega)}{2}\left\{\sqrt{1+\left[\frac{\varepsilon_{n_{z}}^{\prime \prime}(\omega)}{\varepsilon_{n_{z}}^{\prime}(\omega)}\right]^{2}}-1\right\}}
$$

In addition to relative dynamic permittivity, Figure 5 shows dependencies of the absorption index on the reduced energy of external electromagnetic radiation for the observed ultrathin film.
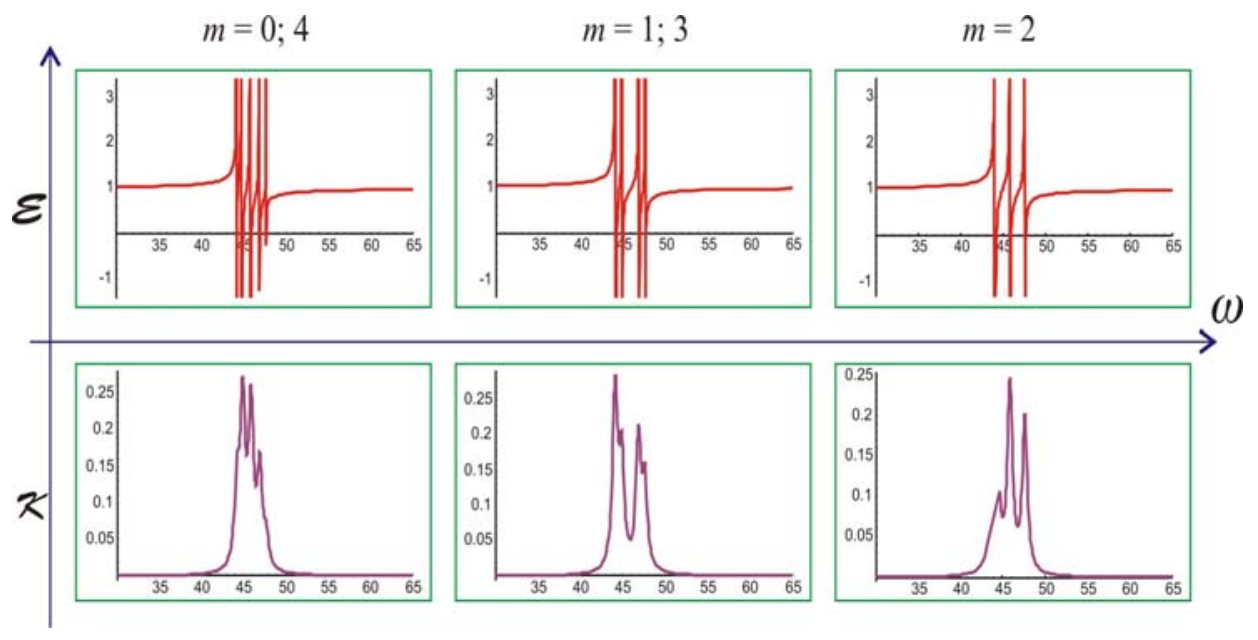

Figure 5. Relative permittivity and absorption index of perturbed symmetrical four-layer film.

All figures present dependence of permittivity and absorption index on reduced frequency of external electromagnetic field for external (border) surfaces, the first external and the middle crystallographic plane. The occurrence of resonant peaks, i.e. the number and distribution of which depends on a large degree on border perturbation parameters.

The first figure above with 3 graphs presents permittivity of an ideal ultrathin film (when perturbation parameters $d$, and $x$ are not changed) with 5 atomic planes along the $\mathrm{z}$-direction. A more detailed analysis of influence of perturbation parameters was dealt with in the previous paper [18]. In this paper we will concentrate on the analysis of absorption characteristics of the observed film-structure.

In the second row of Figure 5, there are presented the dependencies of the absorption index on reduced frequency of external electromagnetic field for four-layer dielectric film. We can see from this that the number of resonant peaks depends on the number, i.e. position of atomic plane $n_{z}$ for which 
absorption index is calculated. Likewise, it is noticeable that the number of absorption peaks (the number of ,real“" peaks) is not equal to the number of resonant peaks of relative permittivity (when $\varepsilon\left(\omega_{\mathrm{r}}\right) \rightarrow$ $\pm \infty$ ). This means that absorption is more direct and that there are priority frequencies of external electromagnetic radiation which are fully absorbed. With others, the absorption is only partial.

\section{CONCLUSION}

The results of these analyses have shown significant differences in the dispersion law (microscopic, i.e. quantum properties) and in dielectric response (macroscopic, but dimensional-quantum properties) of excitons between bulk and symmetrical filmstructures, as a sole consequence of limitation of the film along the $z$-direction and existence of perturbation of parameters on border surfaces and border layers of the structure.

1. The energy spectra of excitons in symmetric film are discreet in regard with the number of levels that is equal to the number of film layers.

2. Increase in energy of excitons on border layers, i.e. nodes, moves the spectrum toward higher energies, while the increase in transfer of energy between border and their adjacent internal layers symmetrically spreads the spectrum towards higher and lower energies.

3. The existence of localized (Tamm) states is possible, and their probability is rapidly increased with the increase in the border perturbation parameters.

4. Dielectric response (permittivity) of the film shows the property of selectiveness, i.e. occurrence of discreet resonant absorption lines, whereas the absorption index shows the occurrence of discreet resonant peaks on exactly specified energies, the number and distribution of which depends on the number of layers in the film and on the perturbation parameters. This gives the films an advantage relative to bulk-structures (the dielectric response of which is continual in the certain range of energies) as in these cases films may be used as a kind of filters of the external radiation.

In the future calculations, frequency behaviour of dynamic index of refraction should be found and compared with the absorption index, that is to say, the validity or deviation from the Krammers rule investigated.

It would be extremely interesting to find a luminescent response of ultrathin film to the external electromagnetic radiation of exactly defined frequencies. These materials - molecular crystals, have a potentially big chance of becoming the main candidates from which nanocapsules in the form of sphere shell would be designed. Core-shell model implies that certain medicaments or certain devices (e.g. nano-camera) are found in its core, whereas the shell should have luminescent characteristics and should serve as a carrier of the mentioned core, but also as a marker by means of which it would be possible to successfully track the position of the core-shell nanocapsule in its journey through human organism to the desired destination $[19,20]$.

\section{ACKNOWLEDGEMENTS}

This paper was financially supported by the Ministry of Science and Technological Development of Serbia and the Republic of Srpska, respectively.

\section{REFERENCES}

[1] V. M. Agranovich and V. L. Ginzburg: Crystaloptics with Space Dispersion and Theory of Excitons, Nauka, Moskow 1979, p.43.

[2] D. Lj. Mirjanić, U. F. Kozmidis-Luburić, M. M. Marinković and B. S. Tošić, Can.J.Phys. 60, 1838 (1982).

[3] V. M. Agranovich and B. S. Toshich, Zh.Eksper.Teor.Fiz. 53, 149 (1967).

[4] G. Mahan: Many Particle Physics, Plenum Press, New York 1990, p.518.

[5] G. Rickayzen: Green's Functions and Condensed Matter, Academic Press, London 1980.

[6] U. Kozmidis-Luburić i B. S. Tošić: Optička pobuđenja u materijalnim sredinama (Optical excitations in material substances), Novi Sad University, Novi Sad 2000.

[7] I. E. Dzialoshinski and L. P. Pitaevski, Zh.eksper.teor.Fiz. 36, 1977 (1959).

[8] D. Lj. Mirjanić, B. S. Tošić and J.P.Šetrajčić, FZKAAA 22, 203 (1990).

[9] M. G. Cottam, D. R. Tilley: Introduction to Surface and Superlattice Excitations, University Press, Cambridge 1989.

[10] S. G. Davison, M. Steslicka: Basic Theory of Surface States, Clarendon, Oxford 1996.

[11] D. B. Balagurov, G. C. La Rocca and V.M.Agranovich, arXiv:cond-mat/0302312 vl 15 Feb 2003.

[12] S. Lazarev, Ž. Škrbić, J. P. Šetrajčić, D. Lj. Mirjanić, Lj. Ristovski, J.Phys.Chem.Sol. 58, 793 (1997). 
[13] J. P. Šetrajčić, S. M. Vučenović, D. Lj. Mirjanić, V. D. Sajfert and S. K. Jaćimovski, Materials Science Forum 494, 49 (2005).

[14] Guozhong Cao: Nanostructures and Nanomaterials - Synthesis, Properties and Applications, World Scientific, Singapore 2004.

[15] Ch. Joachim and L. Plevert: Nanosciences - The Invisible Revolution, World Scientific, Singapore 2009.

[16] V. Sajfert, J. P. Šetrajčić, D. Popov and B. S. Tošić, Physica A 353, 217 (2005).

[17] I. D. Vragović, R. Scholz and J. P. Šetrajčić, Mat.Sience Forum 518, 41 (2006).
[18] S. M. Vučenović, D. I. Ilić, J. P. Šetrajčić, V. Sajfert, D. Lj. Mirjanić: Permittivity in Molecular Nanofilms, Mater.Res.Soc.Symp.Proc. Vol. 1017E, PA 1017-DD08-50 (2007).

[19] Y. Pathak, D. Thassu: Drug Delivery Nanoparticles - Formulation and Characterization, Informa, New York 2009.

[20] D. Lj. Mirjanić, A. J. Šetrajčić-Tomić and J. P. Šetrajčić: Shell-Nanostructured Materials for Biopharmacy and Biomedicine, International Conference on Water, Hydrogen Bonding Nanomaterials and Nanomedicine, Banja Luka 2010.

\section{ПОСЕБНОСТИ У ОПТИЧКОЈ АПСОРПЦИЈИ УЛТРАТАНКИХ МОЛЕКУЛСКИХ ФИЛМ-СТРУКТУРА}

Сажетак: У раду су теоријски истраживане промене фундаменталних оптичких особина у симетрично пертурбованим квазидводимензионим структурама - нанофилм молекулским кристалним узорцима. Енергетски спектар и стања екситона, те њихова просторна дистрибуција дуж осе ограничења (по слојевима), нађен је прилагођеном методом Гринових функција и аналитичко-нумеричким прорачунима. Одређена је релативна пермитивност и истражен утицај граничних параметара на појаву резонантне апсорпције. Нађена је зависност индекса апсорпције од фреквенције спољашњег електромагнетног поља и дефинисана селективна апсорпција код нанофилмова са симетричним граничним површинама.

Кључне ријечи: екситони, наноструктуре, Гринове функције, пермитивност, индекс апсорпције, резонантна апсорпција. 